\title{
Tembiasakue Rapê: a longa estrada Guarani na história e na memória - reconstruindo o passado, ressignificando o presente e trilhando o futuro
}

\author{
Almires Martins Machado ${ }^{1}$ \\ Rosalvo Ivarra Ortiz ${ }^{2}$
}

DOI: http://dx.doi.org/10.20435/tellus.v18i37.500

Ao longo dos séculos, o Guarani foi visto como objeto de estudo e do direito, sendo-Ihe negada a característica de agente de sua própria memória/ história/narrativa, como protagonista dinâmico, ativo e consequentemente sem espaço para manifestar-se, era o indígena domesticado sobressaindo à imagem genérica construída pelo senso comum ao longo da trágica história que todos já conhecem. Entretanto, assim como os demais seres humanos que habitam a imensidão do planeta terra, enquanto indígenas temos o passado bem vivo na nossa memória e na capacidade de reconstituir o nosso passado; nosso futuro depende muito da habilidade de compreender e tirar boas lições do que nos aconteceu em outrora. O passado é relembrado por meio das narrativas na fala dos tujá'i (velhinhos), contadores de história Guarani. Conhecimento que é transmitido nas conversas na opy (casa ritual), na beira do fogo quando dos acampamentos de pescaria, caçadas ou ainda nos momentos em que seus olhos e alma parecem voltar no tempo, e as narrativas fluem como as águas de um igarapé, adentrando a noite. Para que nosso modo de vida percorra outros modos de narrar o passado e o presente, busca-se a qualificação nos meios acadêmicos, uma abrangência maior de conhecimento enquanto sociedade Guarani, e as interações com a sociedade não indígena, engendrando novos conceitos, experiências interpretativas sobre o outro e o que foi dito sobre nós de forma autoritária e violento.

\footnotetext{
${ }^{1}$ Núcleo Jurídico do Instituto Indígena Brasileiro para a Propriedade Intelectual (INBRAPI), Brasília, DF, Brasil.

${ }^{2}$ Universidade Federal da Grande Dourados (UFGD), Dourados, Mato Grosso do Sul, Brasil.
} 
É uma tentativa de compreender, traduzir e a posteriori interpretar, para conhecerem-se melhor ambas as sociedades e ampliar os horizontes de conhecimentos e possibilidades, sabendo de antemão que essas aproximações humanas não são tão tranquilas quanto parecem ser. Ser mediador dessa realidade não é nada fácil, ou seja, é um grande desafio.

Com isso se quer inquirir por onde trilhar o pensamento do indígena hodierno, no caso em tela o Guarani Mbya do Tekoá Pyaú, no município de Rondon do Pará, PA. Como produzir um discurso com as próprias palavras, no qual se enxerga como um reflexo nesse discurso e ao mesmo tempo refletindo no e sobre o "outro"? O discurso que ele produziu sobre o modo de vida Guarani Mbyá, aqui considerando as palavras do "outro" não indígena e os resultados de sua escrita em relação a nós.

Ainda há uma lacuna na academia, falta mesmo de interlocutores teóricos indígenas (está aos poucos vem sendo preenchida), para expressar o nhe'ê/ayvu (linguagem) dos rituais, de outra sensibilidade ou epistemologia indígena e, nesse caso, a Guarani Mbya, para investigar, organizar, processar dados, debater e, sob o ponto de vista da etnologia, o desenvolvimento de uma técnica que irá se aprimorando conforme a pesquisa acadêmica avança, nos procedimentos etnográficos, evidenciando uma crescente maturidade no campo do conhecimento, dando consistência à reflexão teórica sobre principalmente a alteridade, pois há os que nos estudam sem ter adentrado consistentemente em nosso mundo, e há outros que entenderam nosso teko (modo de vida), sem ter-nos estudado, mas convivido conosco (afirmação não se quer de modo algum menosprezar o que foi produzido, e sim olhar de dentro para fora). Há que se reconhecer o esforço e o trabalho escrito de muitos estudiosos do Guarani, que nos legou uma farta literatura sobre nós.

A pretensão é a de lançar um olhar de quem nasceu, vivencia o que estuda (as discussões são coletivas), sem necessariamente usar das explicações dominantes na academia, claro que se moldando a esta possa, quem sabe, dar indicações de nuances que passaram despercebidas.

Desde o primeiro contato com o europeu, a premência das divagações era se os habitantes do novo mundo possuíam direitos, alma ou se eram gente, vistos como uma cultura incapaz, nascendo aí à problemática jurídica de como regula- 
mentar as relações sociais entre conquistador e conquistado. Pulavam os conflitos de interpretação sobre quem seriam os índios? São humanos? Possuem direitos?

Decorrido séculos, é importante observar na atualidade contemporânea, dada a visibilidade política que as populações indígenas vêm conquistando, novas reflexões devem ser feitas, estas indicam, cada vez mais, a necessidade de se reconsiderar a maneira de pensar, a visão que a sociedade não indígena tem das sociedades indígenas. Os velhos estigmas devem ser superados, para assim se terem novos marcos de como conceituar o outro. Os pressupostos para se pensar a questão indígena vão além das oposições entre vencedores ou vencidos, dominantes e dominados, que acabam deixando para as sociedades indígenas apenas dois papéis em princípio: os de vítimas de aniquilação e o de mártires conservadores da cultura (PACHECO, 2006). Se alteridade implica colocar-se no lugar do outro, ouvir o outro como seu igual, reconhecê-lo, embora diferente, isso não aconteceu durante o período da conquista da nova terra.

Para Pierre Clastres (1990, p. 16): "é necessário aceitar a ideia de que a negação não significa um nada e de que, quando o espelho não nos devolve a imagem, isso não prova que não haja nada a observar". Para se compreender o outro, que nesse caso é o indígena, faz-se necessário entender o seu conceito de direito, justiça, a reciprocidade por ele aplicada, ter o olhar um pouco além do terreiro da casa e se adentrar na religiosidade e na cosmovisão.

Cosmologia, segundo Lopes da Silva (1995), é a teoria sobre o mundo e sua ordem, seu movimento no espaço e no tempo, no qual, sob a ótica dos indígenas, a humanidade é um dos muitos personagens em cena. O Guarani crê que possui duas almas, uma humana e outra animal. A cosmologia define o lugar da humanidade nesse cosmos e expressa as concepções sobre natureza, o homem e os deuses, revelando as interdependências e reciprocidades entre os diversos personagens que compõem o mundo material e espiritual, a espiritualidade Guarani se expressa por meio de seus rituais, música, mitos, grafismos, cânticos e artes. O ritual é um momento privilegiado de contato com o universo mais amplo, de interação entre o sobrenatural, a natureza e os homens. É, ainda, o momento de integração interna, de superação das divisões e das divergências, reafirmando a solidariedade e a reciprocidade. São momentos importantes de redistribuição da colheita porque momentos, também, de festa. A Cosmologia e narrativas 
(mitos), associadas são produtos e meios da reflexão de um povo sobre sua vida, sua sociedade e sua história. Expressam concepções e experiências. Constroem e reconstroem-se ao longo dos séculos, dialogando com as alterações, novidades trazidas pelo fluir do tempo, pelo movimentar-se em novos espaços, pelo contracenar com novos autores.

Hodiernamente, o problema continua na indagação se determinado indivíduo é ou não indígena? É ou não sujeito de direito em relação à terra de ocupação tradicional? É aldeado ou "urbano"? De vivência tradicional ou aculturada? "Puro" ou "mestiço"? Não se atenta para o fato de que os povos indígenas têm suas próprias formas de pensar a política, insurgindo contra estes modelos idealizados para si pelo outro, com isso surge o estigma, estereótipos, que faz os povos indígenas serem vistos com desdém, irritação, como estorvo, bêbados, vagabundos, preguiçosos (MACHADO, 2007, p. 155).

Pressupõe-se que lugar de índio é nas matas, nas aldeias, caçando, pescando, coletando, que é o que índio de "verdade" sabe fazer, e não envolvido com questões políticas que exigem cumprimento de seus direitos. Não se atenta para o fato de que os povos indígenas constroem seus processos de autonomia, têm seus projetos de futuro pensados a partir de sua cosmogonia, mas não limitados pela preservação cultural, reivindicam espaço próprio de discussão, participação na construção da nação da qual fazem parte.

A construção e reconstrução da pessoa Guarani são influenciadas pelos acontecimentos ao seu redor, porém os princípios valorativos são de sua matriz religiosa. Calcado na sua espiritualidade, o seu alicerce é a sua cosmologia. Essa construção ocorre também pelo olhar do outro, não que isso não influencie internamente na comunidade, mas projeta um indígena estigmatizado.

Então, se têm dois tipos culturalmente construídos, dois olhares sobre a mesma pessoa: o indígena que reinterpreta valores externos e enriquece a sua cultura (lógica indígena) e o indígena visto pelo olhar de quem está fora da terra indígena, da vivência cotidiana, que o vê como aculturado (lógica racional do não índio). A reprodução pelo indígena de suas categorias culturais específicas é constantemente reelaborada na contemporaneidade, no parentesco, no sistema de chefia e na economia de reciprocidade. Isso é mais perceptível nas comunidades que estão em intenso contato com o não indígena, e nos casos em que a cidade 
veio até a aldeia, expandiu, cresceu até chegar nos limites da terra indígena. Há uma busca pelo que é bom e, se no momento seguinte isso não é mais interessante, o lógico é deixar para trás, desviar-se do que é prejudicial.

É sedimentado na antropologia o fato de que a análise da cultura deve ser norteada pela tradição e memória, induzindo um leitor desatento à ideia de imutabilidade de usos e costumes, como se a cultura não fosse dinâmica, impulsionado pelo pressuposto de que, em contato com o branco, determinada cultura estaria em risco de perder certas características de seu modo tradicional de ser, resultando daí uma aculturação, resultado da friç̧ão interétnica (CARDOSO DE OLIVEIRA, 1996, p. 46-7).

Deve-se levar em conta, entretanto, a reinterpretação, ressignificações da cultura que os povos indígenas promovem para estar e conviver com o meio em que estão inseridos seja urbano ou rural. As construções e desconstruções que os indígenas, entre os quais o guarani, promovem em relação às suas representações de cultura e da cultura do outro, ora acolhendo, ora rejeitando, não fazem dele mais ou menos Guarani. Os esquemas culturais são reordenados de acordo com os acontecimentos históricos, conforme a sua cosmologia, fato que vai aos poucos refletindo na sua organização social e nas relações interétnicas.

Em todo o contato entre povos diferentes, se não forem respeitados os princípios básicos de existência das sociedades envolvidas, haverá uma relação desigual na convivência que se quer estabelecer, entre dois povos distintos no seu modo de entender o mundo. A lógica é que se busque a estabilidade e segurança nas relações, que não podem pautar-se pelo etnocentrismo (ROCHA, 2007), muito menos por verdades absolutas; caso isso venha a ocorrer, haverá um gritante desrespeito aos direitos humanos.

Identidade e alteridade caminham juntas, assim como a semelhança/diferença, estão sempre se acercando de comparações entre uma cultura e outra, o que quase sempre redunda em conflitos de olhares, juízo de valores dissonantes, mesmo porque as pessoas são diferentes. Cada qual com os seus valores de acordo com o meio cultural em que nasceram e foram educados. Sempre existirá o diferente, dois juízos sobre um mesmo fato, ainda mais se tratando de dois povos diferentes (não inferiores), o que não impede o conciliação de ideias, desde que as duas partes estejam dispostas ao diálogo. Dependendo de onde o Mbya esti- 
ver ou o Guarani como um todo, é muito significativo os termos classificadores de aparências que soam como se de identidade fossem, apontados pelo "outro", pontos de vista que se abrem ao infinito as apreciações depreciações sobre a diversidade indígena ou de identidade genérica ou não verdadeira.

Para DaMatta (1987, p. 122), o problema reside em que a expressão cultural quando se aproxima de alguma forma de comportamento e de pensamento diferente traz a classificação dessa diferença por meio da hierarquia, por consequência vem a exclusão. A cultura do outro passa a ser usada como forma discriminatória, ou pior, como indício de desvio ou de atraso, tão somente pelo fato de se ter tradições diferentes e/ou desconhecidas.

A incompreensão acarreta equívocos, ser visto sob o prisma da diferença é algo desejável, porém ser analisado sob a óptica da diferença como desigualdade é o primeiro passo para se aniquilar a isonomia de tratamentos e dos direitos humanos indígenas.

O exercício de poder envolve todos os tipos de relações, entre elas as de ordem econômica, religiosa, social, militar etc. Perpassa pelo modo como as pessoas veem o mundo, de como com ele interagem, é que para tudo há significado. No mundo indígena, a centralidade das relações está no parentesco, é o norte que empresta sentido à organização social, estruturando a sociedade. A cultura está sempre em contínua reinterpretação, conforme novos conhecimentos se apresentam, nos contatos com outros povos, nas relações de comércio, trocas e viagens. Se a cultura vai sendo lapidada ou se reinterpretanda, o mesmo ocorre com as estruturas sociais.

O mal entendido permanece nos dias atuais, via senso comum, fortalecendo as raízes do racismo, preconceito, discriminação, que emerge de tempos em tempos com toda força, como uma patologia social, um câncer que expõe todas as agruras da construção da pessoa versadas no etnocentrismo.

Dada as vicissitudes vividas pelos povos indígenas de uma forma geral, sendo expulsos das terras originárias pela força das armas, prevalece, no entanto, o sentimento de unidade étnica no cotidiano de desterrado. No caso Guarani, inúmeros são os relatos de superação arraigadas na fé inamovível de alcançar a yvy ju (terra madura), ainda todas as circunstâncias levassem a descrer em tal ícone da religiosidade, mas crer sempre foi característica do Guarani; dessa forma, se 
reconstrói o teko (modo de vida), passando a significar lugar para se viver conforme a percepção de Guarani, embora seja do livre arbítrio de cada um viver ou não, conforme tais preceitos, estes são ensinados nas caminhadas educativas pela terra/território, nas noites de jerojy (dançar), na opy (casa ritual) ou em qualquer lugar quando duas ou mais pessoas sentam para conversar.

É o lugar da vida; é a interação do espaço físico com o social, resultando em vida de forma o mais próximo possível ao tradicional e não importa onde se está se na terra "tradicional" ou não, onde se estiver, aí poderá ser o seu lugar de morada; é ali que sua vida literalmente caiu, então deve ser exercitado o ser, para isso não é preciso um lugar especifico, mas guaranizado, basta evidenciar o ser, se vai exercitar o teko vai (vida má, ruim) ou se o teko porã (bem viver, conduta condizente com o modo religioso), isso é com cada um, a vida Ihe pertence, cabendo somente a ele ou ela conduzir o seu ser; claro que aí esta implícita a total responsabilidade sobre a opção seguida.

Dessa forma, o Mbya Guarani transforma uma terra, é o procedimento do ser que faz de uma área geográfica ser uma morada com bem viver, ressignificando tudo que o cerca, ademais a terra onde pisa a planta dos seus pés naquele momento pode estar sendo "curada", batizada pelo Nhanderú/Opyguá/Karaí; a partir daquele momento, a terra onde se encontra passa a ser como uma página em branco, na qual será escrita uma nova história. Claro que o local dos ymaguare (ocupação dos antepassados, morada antiga), também chamado de tekoá guaxú (grande território), tem um peso considerável para isso, mas não o é na essência para a vitalidade do ser Guarani nesse caso Mbyá.

O ter para ser não o é, mas o ser que poderá ter sim. Se reifica, descontextualiza e vice-versa. O que importa de fato é sentir-se, estar guarani, independente de onde está a planta dos seus pés. Tem-se clara a noção da desterritorialização ou re-territorialização, assim como das particularidades interativas de ocupação do espaço onde foi aprisionado, assentado, em terras minúsculas, nesse caso as reservas indígenas.

Embora na atualidade muitos já não observem o modo aconselhável de ser e viver o teko porã, há outros tantos que o observam rigidamente. A postura de transformar qualquer lugar em seu lugar, pode estar restrita a alguns lugares específicos, entretanto o maior exemplo aqui é o Tekoa Pyaú. O Mbya se apro- 
xima desse modo de pensar, por outro lado o kaiowá é o que mais se prende ao grande território dos antigos, para ele não há outro lugar para ser pleno, a não ser no território de ocupação milenar ou onde está a morada de seu xiru, e este só aceita seu local de origem.

Muito já se produziu sobre os povos Tupi-Guarani, no entanto os escritos não conseguem dar conta desse mundo guaranizado, que são as terras e reservas indígenas. O seu modo de vida, religião, sempre está um passo à frente dos olhos que os observaram, que escreveram sobre eles. Em razão disso, Shaden (1974, p. 106) discorria:

Um fato que dificulta não pouco a descrição exata da religião Guarani dos grupos existentes no Brasil, quer no tocante à doutrina, quer ao ritual, é a extraordinária variabilidade observada de aldeia em aldeia, de um sacerdote a outro, ou ainda entre os representantes de um mesmo grupo. A sistematização dos elementos daria por si só margem para extensa monografia. As divergências e contradições, mesmo no interior deste subgrupo, desta ou daquela aldeia, são tão numerosas e de tal modo acentuadas que se torna praticamente impossível apresentar a religião tribal em formulações "dogmáticas" ou peremptórias.

A literatura que versa sobre o Guarani, produz no imaginário dos leitores, em razão da afirmação de serem essencialmente religiosos, de que há uma dedicação exclusiva aos rituais religiosos, o que não é verdade, embora se cante e dance, não há uma profusão ritualística, um cotidiano religioso, não se é fanático no sentido etimológico da palavra, depende de cada um, há famílias mais dedicadas, outras menos, ainda há aquelas que se converteram ao cristianismo. Assim, torna-se evidente que a noção religião indígena é incorreta, pois é um terminologia ocidental, os Guarani seguem outra lógica. Se hoje não se constroem mais casas para morar nos moldes tradicionais, como relatado pelos viajantes quinhentistas e seiscentistas, constroem-se com os materiais que se têm à disposição, quando não, são construídas de alvenaria.

Se há uma aculturação material, é um desejo, uma atitude que cabe somente ao Guarani decidir em querer ter ou não materiais industrializados que facilitam a faina diária, e depois, não é isso que os demais humanos fazem? Não se vive mais exclusivamente de caça, pesca ou coleta de frutas e raízes. Há um Guarani do século XXI, com as implicações do milênio, sejam impostas ou desejadas. 
O mundo Guarani sofreu, sofre e continuará a sofrer transformações considerando as influências externas, não se quer viver em uma redoma de vidro, fechados, isolados, trancafiados, como prisioneiros do Estado em reservas indígenas, como foi mencionado no artigo de Machado e Ivarra Ortiz (2018), ao referir-se sobre a trajetória dos objetos sagrados Guarani. Como se quer negar ao guarani o livre arbítrio invocado pelos não indígenas? Embora não seja mais possível viver como nos tempos cabralinos, no entanto se tem a essência dos sistemas tradicionais de ser ou como deveria ser o modo correto de viver, os princípios do nhandetekó (nosso jeito de ser) têm marcação presente, isso não significa que não foram reinterpretados, ressignificados.

Apesar de estarmos no século XXI, o indígena idílico continua nos livros didáticos, então como se discorrerá sobre a história indígena na escola? Sobre a cruzada ou a epopeia Guarani? Sobre as grandes caminhadas? O nhandeteko? Se sobre elas os professores indígenas ou não, pouco ou nada sabem a respeito?

Em outrora nossos avós empreendiam caminhadas em direção à cidade, que na época demorava meio-dia de caminhada, andávamos sob a copa das árvores, muita floresta, fruta, água límpida e fresca; caça e pesca em abundância. Íamos, voltávamos de qualquer lugar, nossos pés não tinham nenhum impedimento, ainda que fosse empreender o guata (caminhar) para tekoás (lugar de morada) do Paraguai, não havia contratempos outros que aqueles que a natureza impunha. Descansávamos ou dormíamos em qualquer lugar do caminho onde escurecesse, pois não havia perigos maiores que os apresentados pela natureza.

Agora a terra perdeu seus cabelos, não há florestas, caça, pesca, frutas, água limpa, sombra para descansar, o não indígena cercou tudo com arame farpado, marcou sua propriedade com barreiras de modo que o caminhar Guarani aparentemente ficou restringido, além do fato de estar como um animal que é jogado em um cercado, que são as reservas indígenas, cevado para o abate no desterro da prisão de arame farpado. A partir desse postulado, emerge outra pergunta, os Guarani não são mais indígenas originais como os Yanomani (ver Bruce Albert), Araweté (ver Viveiros de Castro), Paracanã (ver Fausto). O oguatá (caminhada) ficou restringindo, porém novas formas de realizá-lo surgiram, pois, caminhar é a marca registrada do Guarani.

Nas narrativas transmitidas ao redor da fogueira, nas noites frias, assando nas brasas a mandioca, a batata, banana, milho, cará, amendoim e tomando kaá'y 
(chimarrão), a caminhada empreendida não se restringia apenas a conhecer outros lugares visitando parentes; tem como função arranjar casamentos para os jovens, crescer em conhecimento e sabedoria, empoderar-se dos conhecimentos tradicionais associados à biodiversidade. Embora a cerca de arame farpado tenha chegado com o não indígena, acompanhada de limites de propriedade, fronteiras entre países, estados e municípios, não impede as caminhadas de acontecer ainda que de forma tímida, mesmo as reservas indígenas, as terras indígenas, serem marcadas como espaço de exclusão, os pés Guarani não conhecem fronteiras.

$\mathrm{Na}$ atualidade, inúmeros tekoas Guarani estão próximos ou mesmo inseridos em grandes centros urbanos, mas isto não tem sido motivo de abandonar o nhandereko (modo de ser), ele se reinterpreta e assume o seu lócus na modernidade, como forma de resistência e imanência; as crenças, a mitologia é ressignificada, para continuar resistindo a outros modos de crença e espírito.

Não há uma impassibilidade ou impossibilidade decorrente de que esta permite ao Guarani valer-se de uma constante reedificação em seu ser. Se hoje o não indígena já ocupou todos os espaços físicos, dificultando a mobilidade de antes, quando se acreditava que somente chegando ao oceano e atravessando-o, é que vislumbrariam as portas da terra onde não há morte ou que seria o seu lugar de destino. Hodiernamente, ele se re-territorializa, se reinterpreta e quer se re-encontrar consigo mesmo, nos lugares de onde um dia saiu. Essa também constitui uma das razões de retomadas dos territórios tradicionais, é nesses espaços que se prolonga a continuidade do ser Guarani, enquanto não ocorre o cataclisma que prostrará o mundo.

Enquanto esse tempo não chega, há a necessidade de espaço para viver o mais próximo possível do recomendado pelas divindades. Portanto não importa as dificuldades para tomar posse outra vez na terra que foi morada dos antepassados, estar é o que importa; por essa razão, a persistência que para os não indígenas transforma-se em invasão de terras, perigo ao estado de direito, uma inquietação jurídica e uma ameaça à propriedade privada, para o Guarani o que ocorre é somente o retorno ao local de onde um dia foi obrigado a sair, por força quase sempre do uso de armas de fogo.

O simbolismo da terra sem mal, continua presente, porém com o foco reorientado na vida terrena pelos dois princípios do direito Guarani, a solidariedade 
e a reciprocidade, centrada na vida social; portanto é preciso apossar-se do seu guará (território), para dar continuidade às etapas que levam ao aguyje (iluminação da alma), é preciso, entre outras coisas de alimentação específica, consagrar a terra e as pessoas, para retomar oguatá (caminhada) espiritual e alcançar o estado de espírito perfeito. O mbaraka (chocalho) precisa ser exercitado no locais de origem, os cânticos precisam alçar os caminhos do céu, a alma precisa ficar leve. Se antes se acreditava que poderia alcançá-la pela via terrestre, rumando-se a leste ou oeste e atravessando o mar, hoje se compartilha o pensamento que o caminho é o espiritual. Para tanto, é primordial que tudo volte ao seu lugar de princípio, o território tradicional ou uma terra guaranizada, para poder exercitar o ser numa terra onde é possível o bom viver, a vida com qualidade.

Nessa terra, o exercício desejável é o de viver da forma mais correta possível, para não se deixar levar pela animalidade da alma, em contraste o que vale é o exercício da humanidade, que aproxima do modo de vida dos que estão na terra onde não se morre. Lembrando que esse modo de ser não é exercitado por todos, com dito acima, faz parte do livre arbítrio. É a condição da pessoa que conta; o parentesco pode ser de laços consanguíneos ou construídos nas relações estabelecidas ao longo do guatá (andar), a construção da pessoa é condição de reconhecimento como etarã (parente), demarcando as nuances da sociabilidade, identidade, solidariedade, reciprocidade com os humanos ou com os não humanos; implica estar ou não na memória de quem visita e de quem é visitado, desde que saiba pronunciar corretamente as palavras da etiqueta guarani.

A caminhada marcante não é somente aquela realizada nos espaços geográficos no plano físico, terreno; a mais significativa é a que leva da terra ao céu ou o ambá, unindo visível e invisível, por um marcador chamado mbaraka (chocalho). Uma caminhada ou visita a uma parentela distante pode e quase sempre inicia com um sonho, por isso a importância de ter uma opy (casa ritual) com seu opyguá (orientador espiritual).

Nas caminhadas, exercita-se um saber fazer, um conhecer, um aprendizado, caminha- se por diferentes lugares, adentrando-se segredos da botânica; fauna e flora são esquadrinhadas, no caso de danças para cura, diferentes essências assomam-se para compor o conjunto de um conhecer para saber fazer. Não é simplesmente um caminhar, é uma forma de alcançar a saúde, vida saudável, ter 
conhecimento, não basta somente a vida em si, é preciso que ela flua, assim como a água de um rio. É claro que as formas de conceber as cosmologias transformam-se, nesse percurso são reestruturadas, é incabível a procura por uma tradição pura, elas são legitimadas por seus agentes, para isso tem autonomia, independência tenaz, idônea, para ser ele mesmo com sua religiosidade, com consciência do divino ou em busca de serem iguais as suas divindades.

Ainda nos dias atuais, tem uma excelência em esconder a sua religiosidade, que, como antigamente, desliza por sobre as ondas do silêncio. A religiosidade e os conhecimentos tradicionais, associados ou não à biodiversidade, foram e são constantemente recriados e reorganizados, ressignificados. Não é um processo simples, considerando que agrega em seu bojo toda a cosmologia do ser que redunda na vida Guarani, na construção da pessoa.

Não basta o reconhecimento da diferença, é necessário prover formas de coexistência considerando a alteridade: A ideia do relativismo, multiculturalismo, direitos humanos, remete às identidades coletivas na perspectiva da construção de novos paradigmas que de fato construam a cidadania, efetivando o reconhecimento da diferença e do direito à diferença e de ser diferente.

Para tanto é preciso alargar os caminhos que promovam direitos humanos, identidades e cidadania. Apesar das nuvens esvoaçarem o céu do entendimento, é o desrespeito ao modo de ser dos povos indígenas e o não reconhecimento destes como sujeito de direito, por grande parcela da sociedade nacional, não impede que o entendimento seja um objetivo, uma posição a ser conquistada. Mesmo que boa parte das ações promovidas em terra indígena não tenham levado em conta as especificidades do saber local da comunidade, não respeitando ou considerando sua lógica, sua cosmovisão, as ações servem de lição para que o erro não se repita.

O indígena é um ser humano como outro qualquer, como tal tem os seus direitos e quer exercer a sua cidadania; não fosse assim, não teria defendido esta terra contra holandeses, franceses, paraguaios e tantos outros; juntamente com os negros, derramaram sangue para hoje ter as suas raízes fincadas no solo da pátria amada, esta não é exatamente como uma mãe gentil, mas o brado retumbante dos povos indígenas ecoa por direitos e reconhecimento há séculos. Quer tão somente viver em paz, na terra que o viu nascer e crescer; terra da sua origem, 
dos seus mitos, da sua identidade, dos seus heróis ou aquela que foi guaranizada por meio de seu modo de vida e espiritualidade, mas não mais ou menos Guarani.

É preciso que se tenha em mente que mesmo o indígena histórico sempre foi um sujeito atuante, embora apagado de forma hostil como filho da nação brasileira, pelo qual derramou sangue em guerras, permitindo que hoje o país tenha o atual desenho de fronteiras. Sempre foi capaz de tomar decisões em defesa de seus direitos, ainda que fosse necessário pegar em armas. Jamais deixou de costurar alianças, constituir rede de conhecimentos que lhe permitiam não ser uma simples vitima, mas que sempre esteve contrapondo-se a opressão, escravização, exploração e buscando o limiar de seus direitos.

Atualmente, mais indígenas se qualificam e se apresentam no cenário nacional e internacional, como protagonistas de seus direitos e de sua história; continuam negociando, reivindicando, resistindo, propondo soluções a problemas históricos que vivenciam, quando não, são os agentes que denunciam o expresso desrespeito pelos direitos humanos indígenas, fomentados pelo Estado brasileiro e seus agentes.

O velho e o novo convivem nas reservas indígenas, a teia de significados enreda-se no saber local (GEERTZ, 1998), dando forma, fluidez, porosidade, permeabilidade, flexibilidade às fronteiras culturais, reinterpretando, ressignificando, reelaborando a sua cultura, rede social, modo de pensar, ver e agir, conforme a situação o exigir, legitimando-a. Não está passivo, aceitando o papel de vitima, o paradigma da aculturação, de visões estereotipadas, de sujeitos de segunda categoria, de incapaz; o século XXI permite ir muito além do imaginado, tanto que o "índio de verdade", hoje esta nas universidades, faz parte das redes sociais da internet, twitando e trocando informações via facebook, netizado.

As palavras pronunciadas pela liderança indígena Ailton Krenak (1998, p. 23) resume este pensamento:

No mundo todo ainda existem povos tradicionais, na África, na Ásia, Norte da Europa, Norte América, não importa o quanto estejamos afastados dos grandes centros urbanos, temos que responder a tantas perguntas que incluem desde a escola, saúde administração de terras, negócios com terceiros.... Basta esta lista para exemplificar o quanto estamos sendo intimados a criar novas respostas para um grande numero de perguntas nem tão novas assim. 
Novas respostas são cobradas a cada instante em que indígenas se levantam e contestam as situações que estão postas, sem, contudo, serem tão novas, como atesta Krenak; o multiculturalismo e o pluralismo jurídico continuarão a provocar inquietações, enquanto o relativismo não for uma prática, considerando que o universalismo jurídico foi e continua sendo uma imposição. Os povos indígenas continuam com sua marcha rumo a conquistas de direitos, mesmo que a intolerância se intensifique, não será diferente dos velhos tempos, entretanto novas armas estão sendo manuseadas e muito mais potentes no seu alcance do que 0 velho arcabuz ou o arco e a flecha. Que o digam as mídias sociais.

Portanto caminha-se rumo à autonomia, e esta entendida como aquela que se concretiza em dois momentos distintos.

Do ponto de vista legal a autonomia inserida no texto da Constituição Federal (BRASIL, 1988) em especial o art. 231, onde se inserem os dispositivos basilares promotores do princípio e do reconhecimento da autodeterminação. Em tela destacam-se as previsões delineadoras do reconhecimento da organização social, costumes, línguas, crenças e direitos originários sobre as terras que tradicionalmente são ocupados pelos povos indígenas. Cabe ao Estado o dever de demarcar e proteger as terras indígenas que pertencem à União; razão de os povos indígenas protestarem pela demarcação de suas terras e recorrerem à última instância jurídica, o Supremo Tribunal Federal (STF), para fazer valer seu direito a terra.

Segundo, ao reconhecer e determinar o respeito à organização social e às terras de cada povo, reconhece também a pluralidade jurídica, mais que isso valida os efeitos do Direito vigente internamente, em cada comunidade. Nesse front de lutas, cada povo tomará a Constituição Federal para fazer valer o seu Direito, interpretando de acordo com os seus valores culturais e pelo que dita a sua cosmologia. Nesse âmbito, o Direito deve ser buscado nas mais diversas frentes de luta, seja no campo da saúde, alimentação, educação, proteção e preservação da natureza, dos ecossistemas e biomas, sempre ameaçados pela ocupação desordenada do entorno das terras indígenas pelo branco. O conceito de autonomia é constantemente reinterpretado, com isso amplia o horizonte dos objetivos a serem alcançados, como por exemplo, estar mais presente nas discussões que dizem respeito a si e seus interesses futuros, estar nos ministérios para cobrar do Estado Brasileiro o respeito e o cumprimento do preceituado na norma maior. 
Não se resigna mais a ser objeto de direito, e sim reclama o protagonismo político, sua participação no momento de debater as políticas públicas, aplicação de mecanismo de desenvolvimento limpos (MDL) ou do chamado etnomanejo de seus recursos naturais, de sua biodiversidade. Reclama, protesta em razão de não ser consultado, considerando a previsão legal, sobre os grandes projetos em execução pelo governo Federal, em razão de serem alcançados pelos efeitos dos impactos, seja direto ou indireto, do Plano de Aceleração do Crescimento (PAC), entenda-se barragens. Isto também implica a busca da terra do bom viver ou ainda que esteja tentando arrefecer os efeitos dos males causados por tantas outras pessoas.

Essas demandas políticas hoje fazem parte do empoderamento, de todas etnias brasileiras, no entanto em relação ao guarani, para poder alcançar a terra sem mal, ele tem que garantir legalmente seu espaço físico, pois o caminhar para novas terras já não é possível e considerando que o Juruá (branco), está se apossando de toda e qualquer terra, com uma voracidade extrema, o Guarani tem que lutar para ter demarcada a terra que está em sua posse ou aquelas que reivindica. Com isso vamos re-interpretar a forma de caminhar, teremos manter formatadas as redes de tekoas (lugar de morada), por todo o país, e somente pela demarcação isso é possível e assim acabar com os acampamentos as margens de rodovias.

Alcançando essa meta, estará garantido um pedaço do corpo da mãe terra a futura geração e a caminhada será de opy (casa ritual) para opy, de tekoá a tekoa (lugar de morada), formatando um tekoa guaxú (grande território), não de apoderamento, mas de visitações, pois com morada fixa, ter-se-ão condiçoes de pleitear das autoridades governamentais as condições favoráveis ao bem viver, ainda que os orientadores espirituais não guardem semelhanças com os do passado na aparência, mas o serão na essência. Os novos tempos exigem muito mais que adaptação, exigem recrudescimento do mimetismo que permitiu ao guarani chegar nos dias atuais preservando a memória e os ensinamentos dos ancestrais, o modo de crer e ser, ainda que incorporando novos costumes e hábitos.

O sonhar continua no cotidiano do guarani, ouvir, ver, fazer e imitar referidos ao longo da escrita, liames da educação Guarani, continuam vivos, enveredando pelos caminhos do conhecimento acadêmico em todas as áreas da intelectualidade, para garantir o bem viver, sem abrir mão da liberdade de caminhar e agora 
do empoderamento político e econômico, porém o mais almejado é a garantia da educação com metodologias e pedagogias próprias. Portanto todas as nuances de reivindicações, apontam para as características de uma terra ainda que imperfeita, porém gradualmente curada, reconstruída, ritualizada, guaranizada e por fim yvy marãe "y (sem mal) terrena, pois a espiritual continua sendo visitada a cada sonho ou nos rituais realizados seja na opy (casa ritual) ou nos acampamentos às margens de rodovias, nos acampamentos.

Portanto, para finalizarmos minimamente, corroboramos que todos esses esforços se direcionam no sentido de garantir a demarcação, assim se terão dezenas e dezenas de tekoas (lugar de morada), para estabelecer parentesco e uma rede de caminhos possíveis de trilhar e evitar ou somente ficar com o que diz o título do artigo de Jorge Eremites de Oliveira e Levi Marques Pereira (2007): Duas no pé e uma na bunda.

\section{REFERÊNCIAS}

BRASIL. Constituição da República Federativa do Brasil. Brasília, DF: Centro Gráfico do Senado Federal, 1988. 292p.

CARDOSO DE OLIVEIRA, R. Índio e o mundo dos brancos. Campinas, SP: UNICAMP, 1996. CLASTRES, P. A sociedade contra o Estado. 5. ed. Rio de Janeiro: Francisco Alves, 1990. DAMATTA, R. Explorações: ensaio de sociologia interpretativa. Rio de Janeiro: Rocco, 1987. EREMITES DE OLIVEIRA, J.; PEREIRA, L. M. "Duas no pé e uma na bunda": da participação terena na guerra entre o Paraguai e a Tríplice Aliança à luta pela ampliação dos limites da Terra Indígena Buriti. Revista Eletrônica História em Reflexão, Dourados, MS, v. 1, n. 2, p. 1-20, jul./dez. 2007.

GEERTZ, C. O saber local. Novos ensaios de Antropologia interpretativa. Petrópolis, RJ: Vozes, 1998.

KRENAK, A. Novas exigências globais e realidades indígenas regionais. Belo Horizonte: Bay, 1998.

LOPES DA SILVA, A. Mito, razão, história e sociedade. In: LOPES DA SILVA, A.; GRUPIONI, L. D. B. (Org.). A temática indígena na escola. Brasília: MEC/MARI/Unesco, 1995.

MACHADO, A. M. De incapaz a mestrando. Revista Tellus, Campo Grande, MS, ano 7, n. 13, p. 155-61, out. 2007. 
MACHADO, A. M.; IVARRA ORTIZ, R. Mbaraka ju: arte, memória e fala sagrada Guarani. REA - Revista Euroamericana de Antropología, Salamanca, n. 5, p. 73-81, 2018.

PACHECO, R. A. S. Direito indígena: da pluralidade cultural a pluralidade jurídica. Revista Tellus, Campo Grande, MS, ano 6, n. 11, p. 121-44, out. 2006.

ROCHA, E. O que é etnocentrismo. São Paulo? Brasiliense, 2007.

SHADEN, E. Aspectos fundamentais da cultura Guarani. São Paulo: Difusão Europeia do Livro, 1974.

\section{Sobre os autores:}

Almires Martins Machado: Doutor em Antropologia e Mestre em Direitos Humanos pela Universidade Federal do Pará (UFPA). Graduado em Direito pelo Centro Universitário da Grande Dourados (UNIGRAN). Membro do Núcleo Jurídico do Instituto Indígena Brasileiro para a Propriedade Intelectual (INBRAPI). Pertencente à etnia Guarani e Terena. E-mail: ateguara@gmail.com

Rosalvo Ivarra Ortiz: Mestrando em Antropologia Sociocultural e Graduado em Licenciatura Plena em Ciências Sociais pela Universidade Federal da Grande Dourados (UFGD). É membro do grupo de pesquisa Grupo Iberoamericano para Pesquisa e Difusão da Antropologia Sociocultural (GIPEDAS). Possui artigos publicados no Brasil e na Europa. Filho de indígena Guarani. Pesquisa arte, memória e cosmologia Guarani em Mato Grosso do Sul. Bolsista: FUNDECT/MS. E-mail: rosalvortiz@hotmail.com

\section{Recebido em 9 de junho de 2018}

Aprovado para publicação em 2 de julho de 2018 
